\title{
A DESIGN FRAMEWORK FOR ELECTRONIC COGNITIVE APPRENTICESHIP
}

\author{
Feng-Kwei Wang, Ph.D. \\ Assistant Professor \\ School of Information Science and Learning Technologies \\ 20 Rothwell Gym \\ University of Missouri - Columbia \\ Columbia, MO 65211 \\ Phone: (573) 884-3918 \\ wangfeng@missouri.edu
}

Curtis J. Bonk, Ph.D.

\author{
Associate Professor \\ Department of Counseling and Educational Psychology \\ School of Education: Room 4022 \\ Indiana University \\ Bloomington, IN 47405-1006 \\ Phone: (812) 856-8353 \\ cjbonk@indiana.edu
}

\begin{abstract}
This paper proposes a design framework for constructing a groupware-based learning environment (GBLE) that enables electronic cognitive apprenticeship. The central theme of this framework is that any design of a GBLE must have learning theories as foundations to substantiate the learning effectiveness of this environment. The proposed framework applies the principles of cognitive apprenticeship and casebased learning in designing a learning environment using groupware technology. In this framework, the practice of case-based learning is grounded in cognitive apprenticeship. The theory base of cognitive apprenticeship provides not only more coherent guidance but also opportunities to fine-tune the pedagogy of case-based learning. Groupware tools provide needed functions to enable instructional methods of cognitive apprenticeship. This technological support also facilitates the learning process of learners and thus enhances the effectiveness of case-based learning. Based on this framework, a system titled "Using Notes for a Case-based Learning Environment" (UNCLE) was created to demonstrate the framework's utility.
\end{abstract}

\section{KEYWORDS}

Cognitive apprenticeship, case-base learning, groupware, groupware, learning environment

\section{INTRODUCTION}

For those interested in the potential impact of educational technology on human learning, these indeed are interesting times. Salomon [1], in fact, suggests that this is the first time that technological advancements are outpacing pedagogical and psychological theory. Nevertheless, new psychological developments have now emerged that can take advantages of collaborative, distributed, and interactive educational technologies. Of course, in the past, the field of instructional technology placed a heavy emphasis on the improvement of technology, including processes and methodologies for instructional deliveries [2][3]. 
This instructional delivery focus aimed to "design instructional systems that transmits content and skills in a clear, well-structured, and efficient manner" [4, p.347]. However, recent emerging learning theories such as situated learning [5][6][7] and cognitive apprenticeship [8] have brought about considerable changes in the views of instructional technology. These changes shift the design of instructional systems from teaching to learning and from instructional objectives to facilitative environments. They also have tremendous influences in the design of technology-based learning environments [9].

This paper intends to demonstrate how these emerging learning theories can be applied in the construction of an asynchronous learning environment using groupware technology, thus called a groupware-based learning environment (GBLE). We use a GBLE that we created as an example. The system was titled -"Using Notes for Case-based Learning Environments" (UNCLE). We begin with an overview of cognitive apprenticeship, case-based learning, and groupware technology, which UNCLE was built upon. Then, we introduce the design framework of UNCLE, followed by the explication of GBLE tools and operations in support of cognitive apprenticeship. Lastly, the actual screen shots of UNCLE are presented to give readers a better understanding of designing a GBLE.

\section{A. Cognitive Apprenticeship}

Cognitive apprenticeship draws its inspiration from traditional apprenticeship and creates a meaningful social context in which learners are given many opportunities to observe and learn expert practices. By enculturating learners into authentic practices through activities and social interaction, they are able to develop the cognitive skills of practitioners [5]. According to Collins, Brown and Newman [8], cognitive apprenticeship emphasizes the solving of real world problems under expert guidance that fosters cognitive and metacognitive skills and processes. To put cognitive apprenticeship into practice, Collins et al. [8] offered six instructional methods of cognitive apprenticeship - modeling, coaching, scaffolding, articulation, reflection, and exploration. Based on the innovative work of Tharp [10] and Tharp and Gallimore [11] related to assisting in the learning process, Bonk and Kim [12] recently elaborated and expanded on the cognitive apprenticeship framework to include questioning, task structuring, performance feedback or management, and direct instruction when appropriate. Importantly, this revised framework was designed for adult learning environments. The original six methods are summarized in Table 1.

Table 1. The six instructional methods of cognitive apprenticeship (excerpted from [8])

Modeling provides opportunities for students to observe an expert's practices. The learning situation must include exemplars of how an expert performs the tasks.

Coaching offers students help in the form of hints, scaffolding, feedback, modeling, goal setting and reminders while they are carrying out tasks.

Scaffolding provides temporary support by teachers for those parts of the tasks students have difficulty performing. The support can take the forms of suggestions or direct help. Fading consists of the gradual removal of this support until students are on their own.

Articulation requires that students explicitly express their knowledge, reasoning, or problem solving processes for problems or issues that they are tackling. Articulations can include students engaging in a dialogue, verbalizing their thoughts, or assuming the role of monitor or critic in cooperative activities.

Reflection offers a mechanism for students to externalize their metacognitive processes and hence open them for evaluation. It enables them to compare their own problem-solving processes with those of an expert and other students.

Exploration invites students to tackle and solve problems independently. Usually, instructors set general goals and teach exploration strategies. Students then are encouraged to focus on particular sub-goals within learning tasks, or even revise the general goals in order to come up with their own problem solutions. 
The notion of guided experience in cognitive apprenticeship corresponds to the concept of guidance and collaboration in the zone of proximal development (ZPD) introduced by Vygotsky [13].

It is the distance between the actual developmental level as determined by independent problem solving and the level of potential development as determined through problem solving under adult guidance or in collaboration with more capable peers (p.86).

From this perspective, the ZPD develops through the assistance of experts and more able peers in a specific social system. Exposure to the strategies, skills, and ideas of others on a social plane can be individually appropriated and internalized as independent problem solving skills. The implication is that, to learn better, learners have to be situated in the social and functional context embedded with the learning skills and knowledge. In this paper, case-based learning tools and features are described that are based on the sociocultural views of Vygotsky.

\section{B. Case-based Learning}

As a methodology of instruction, case-based learning ${ }^{1}$ has long been believed by most educators and trainers to be a powerful method [14][15][16][17][18]. The use of paper-based cases has been accepted practice in many professional disciplines such as business, law, medicine, and education for decades [19]. Case formats include simple narratives, cases with alternative or counter scenarios, cases with expert commentaries, cases with purposefully embedded flaws, and cases that build or become more complex [20]. A recent trend is the use of cases with videotapes, videodiscs, CD-ROM, computer conferencing, and other media. Computer conferencing, for instance, might include learners from all over the world discussing and debating issues or problems of interest [21]. When learners are dispersed across great distances or time zones, case-based Web technology is a logical choice since it is inexpensive, controllable, and convenient. During these electronic case discussions and reflections, an instructor might apprentice students into their chosen profession by modeling expert answers, providing feedback, asking questions, and countering misconceptions. Students, in contrast, might work use collaborative tools to discuss cases in team-shared workspaces, synchronous chats, scratch pads or whiteboards, and shared documents [22]. In effect, new technologies for collaboration socially are emerging to create a shared space for sharing, debating, and constructing knowledge.

The effectiveness of this pedagogy is manifested by three important characteristics: (a) real-life problems, (b) the encouragement of learner involvement, and (c) the active application of knowledge and skills. Typically, a case analysis involves the study of a real-life situation and connects learners to the real context. The discussion of a case provides learners with the opportunity to exchange their ideas, share information and resources, and learn from the thought processes of other learners, thus encouraging a team spirit and promoting communication skills. Also, case analyses help learners hone their skills in analysis, judgment, and synthesis. The use of case-based learning in this framework is to build the ZPD where experts or more able peers can help the problem solving process of learners. Learners acquire knowledge and skills through the constant guidance of experts when they solve work-related cases.

\section{CSCW and Groupware}

CSCW (computer supported cooperative work) is a generic term which encompasses "the understanding of how people work in groups with the enabling technologies of computer networks and associated

\footnotetext{
${ }^{1}$ In most of the literature, case-based learning is called case study instruction or case method instruction. Since UNCLE places this pedagogy in creating a learning environment, the focal point moves from the instruction of the instructor to the learning of the learner. Therefore, this pedagogy is called case-based learning.
} 
hardware, software, services and techniques" [23, p.1]. The aim of CSCW is to increase group work effectiveness by supporting group communications and facilitating group activities.

Groupware refers to any technology that supports $\mathrm{CSCW}$ in enhancing group productivity. Ellis, Bibbs, and Rein [24] define groupware as "computer-based systems that support groups of people engaged in a common task (or goal) and that provide an interface to a shared environment." They hold that the ultimate goal of groupware is to mesh business performance, organizational structure, and technology systems into a single platform. It usually contains functions for collaboration, communication, and coordination of group work such as e-mail, computer conferencing, workflow management, document management, calendaring, and co-authoring. Groupware products such as Lotus Notes or Microsoft Exchange have begun to generate productivity gains, which, naturally, have attracted the attention of many corporate users [25], [26]. In the vanguard of pioneering companies are Arthur Anderson, Dell Computer, EDS, IBM, GM, and Price Waterhouse. Today, almost all the Fortune 500 companies have implemented groupware in one form or another.

\section{UNCLE's Design Framework}

While the use of groupware as a means for solving business problems has been perceived as a promising practice for corporate America, the idea of using groupware for educational purposes in the corporate context is still at its infant stage. The first and foremost problem is that commercial groupware products such as Lotus Notes or Microsoft Exchange are designed as business tools primarily meant to facilitate business processes and operations. As a result, most groupware lacks sufficient grounding in learning theory to sustain it as a learning platform. Therefore, as the first step, we developed a design framework (see Figure 1) as the bedrock to effectively convert groupware into learning tools. This framework lays out what is required for learning to be effective and provides coherent guidance for the adaptation of groupware functions for learning purposes.

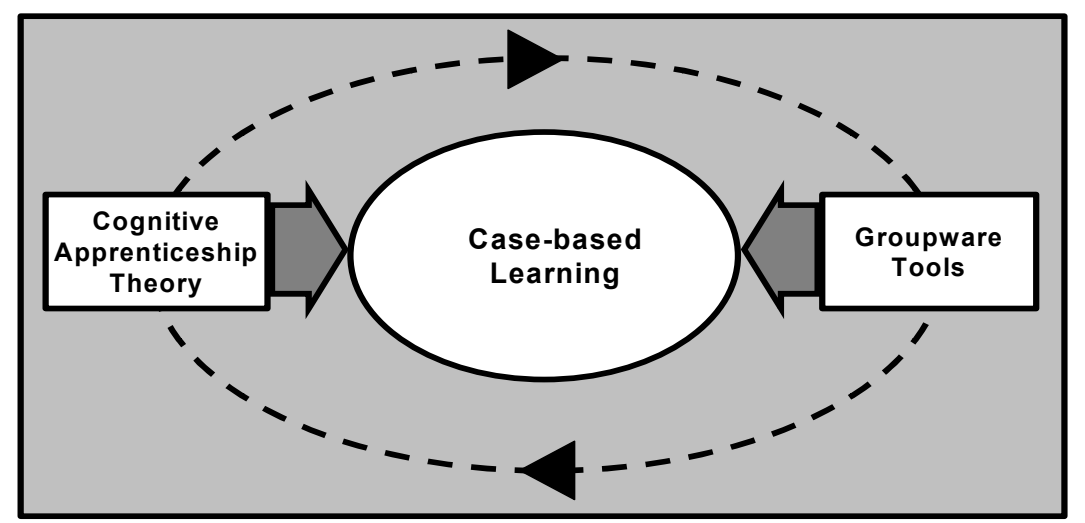

Figure 1. The design framework of a groupware-based learning environment

In this GBLE framework, the practice of case-based learning is grounded in cognitive apprenticeship. The theory base of cognitive apprenticeship provides not only more coherent guidance but also opportunities to fine-tune the pedagogy of case-based learning. Groupware tools provide needed functions to enable instructional methods of cognitive apprenticeship. This technological support also facilitates the learning process of learners and thus enhances the effectiveness of case-based learning. The goal is to advance a learner from a novice to an expert in the ZPD. In this electronic learning environment (see Figure 2), learners build and share knowledge in four ways: (1) through online case-based learning activities with peers and experts, (2) through the utilization of groupware tools, (3) through full-time access to learning resources and results, and (4) through six online instructional supports in cognitive apprenticeship. 


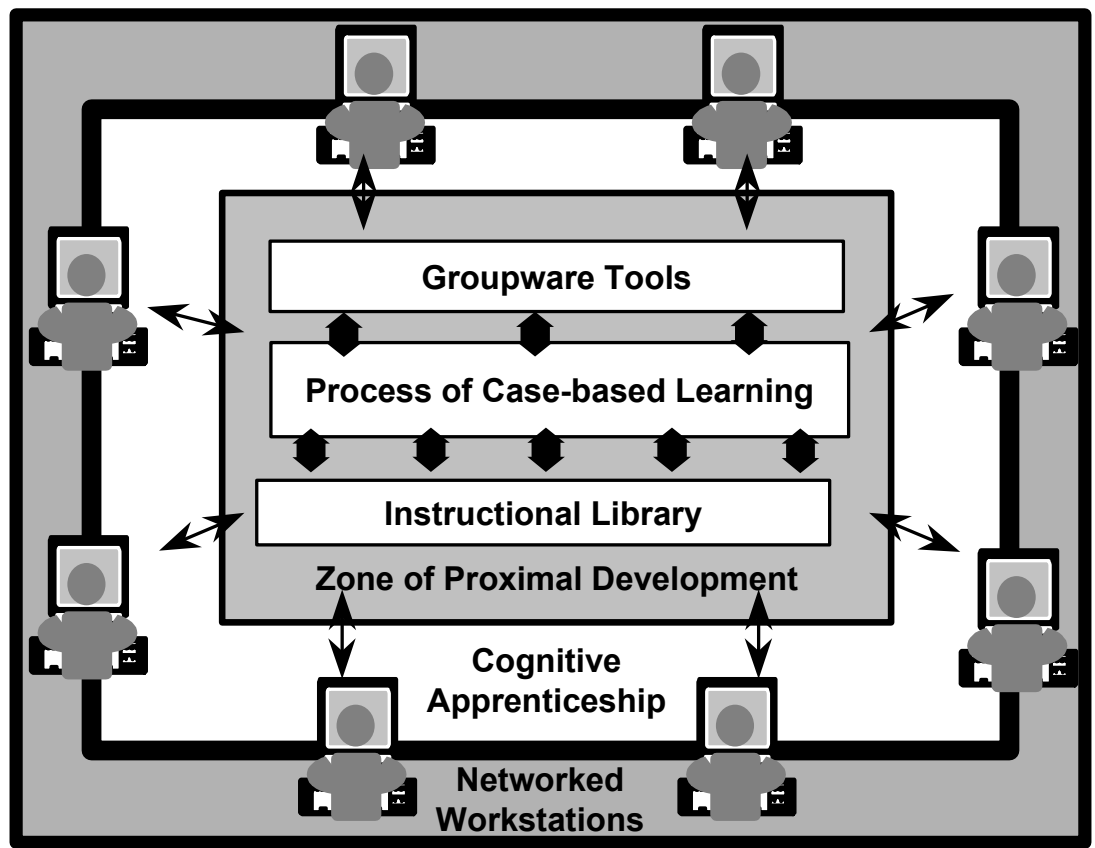

Figure 2. Groupware-based Learning Environment

\section{Groupware Technological Support}

To design a GBLE, groupware functions have to be converted for learning purposes. To accomplish this learning conversion, the tools selected and devised for UNCLE facilitated the pedagogical processes of case-based learning grounded on the six instructional methods of cognitive apprenticeship. As described below, three categories of groupware-based learning tools were devised: (1) collaborative tools, (2) cognitive tools, and (3) the instructional library.

\section{A. Collaborative Tools}

Collaborative tools, which include computer conferencing, electronic mail, and shared workspace, are used to promote communications and collaborations among learners [27]. Learners work in collaborative groups to solve case problems through the online environment built on computer networks. They might also track the progress of other teams or provide timely feedback. Through the networks, multiple perspectives and diverse learning approaches can also be stimulated, with each reinforcing the others [28]. Computer conferencing permits the development of online, asynchronous, many-to-many person discussions. These might be issue-based discussions, informal conversations, or pedagogically staged activities such as debates and role-play. Electronic mail allows each user to send messages relating to personal issues to a specific person or group [29]. Computer conferencing and electronic mail allow learners to break the traditional boundaries of time and place. A shared workspace tool serves as the group memory, recording group activities and information. It is capable of tracking a learner's or a group's associating patterns and learning paths that indicate what actions have been performed and what information has been accessed. Learners can either reflect on their own learning histories, or learn from others by reviewing group processes in computer log files.

\section{B. Cognitive Tools}

Kozma [30] explains that the computer can alleviate the learner's information processing burden, thereby extending human cognition. In case problem solving activities, computer cognitive tools are used to ease 
and enhance the performance of cognitive tasks. Such tools include performance support, hypermedia, and navigation functions. First, performance support functions are a set of computer tools or electronic job aids which learners use to facilitate case problem solving. These functions ease cognitive loads of many arduous but necessary learning tasks and make learning and problem solving more efficient. The use of case analysis forms and online case analysis guidelines in UNCLE are two typical examples. Second, in a hypermedia environment, knowledge is purportedly organized by mirroring the structure of human thinking. The process of imitating human thinking proceeds through associating one piece of information to a related piece of information. It functions as "knowledge on demand" and exhibits the capacity to branch from one thought to related knowledge or experiences [31]. That being so, an appropriately structured hypermedia system should be able to mirror the semantic network of an experienced or knowledgeable performer or expert [32]. Third, navigation functions such as searching, navigation maps, indices, history, and bookmarks prevent learners from getting lost in the spacious knowledge ocean and point learners in the right direction. Navigating with such tools quickly brings learners the part of knowledge that they are looking for. Navigation maps show where learners are and where they have been in knowledge bases. Similarly, indexes offer learners different ways of identifying and viewing knowledge. In contrast, the history function keeps track of navigational paths and allows learners to trace their learning processes. Finally, bookmarks register particular knowledge locations for later quick access.

\section{Instructional Library}

The instructional library is a collection of online instructional materials in an organized and searchable format. It supports case-based learning, cognitive apprenticeship, and on-the-job application, and provides the learning resources of knowledge acquisition, transmission, and expansion. The following are components of the instructional library in UNCLE.

\section{UNCLE's instructional library components}

- Cases which are text- and graphic-based business scenarios related to a particular business domain,

- Domain knowledge which is composed of conceptual and factual knowledge and procedures explicitly identified with the business domain,

- Reflective questions which are case-related questions and are crucial to the understanding of a case,

- Testing questions which evaluate learner understanding of domain knowledge,

- Problem solving strategies which are the methods or procedures modeled by experts or learners to solve particular case problems,

- Problems solving samples which are example case solutions meant to help learners working on a case analysis,

- Expert solutions which are the expert's advice and/or solutions for a case,

- Peer solutions which are the various versions of solutions for a case provided by learners,

- Case analysis guidelines which are the instructions and hints of conducting case-based learning, and

- Online discussion that is the repository of dialogue among learners and experts. 


\section{Electronic Cognitive Apprenticeship}

The UNCLE framework aims to create an electronic cognitive apprenticeship environment using groupware technology to support the pedagogical process of case-based learning. This environment makes it possible to give more attention to individual learners, which effectuates the coaching and scaffolding of apprenticeship-style learning. It also makes modeling, coaching, and fading more costeffective and widely available [8]. In addition, electronic apprenticeship creates a collaborative learning environment and augments the dialogue among learners and experts through online communication and collaboration tools. In effect, this forges a mechanism for knowledge adoption and diffusion without the temporal and geographic limitations.

\section{A. Modeling}

Williams [18] argues that, with expert models, learners learn problem-solving strategies more quickly and effectively and without having to go through the personal struggles of trial and error testing which too often results in less-effective strategies. The modeling method suggested by cognitive apprenticeship gives learners opportunities to observe the problem solving processes of an expert. These opportunities provide learners with an overall mental model of the task that they are trying to learn, as well as demonstrate how an expert uses domain knowledge and strategies to solve problems. Fortunately, the mental model and problem solving strategies of experts can be effectively represented on a computer. For example, digital video can be used to demonstrate how an expert analyzes and solves a problem. Online expert solutions, moreover, can be available for learners to observe. Expert strategies can be articulated verbally or graphically and then stored online for learners to view and grasp expert thinking and behaviors. In this way, learners are able to see an expert in action and discuss expert performance.

\section{B. Coaching}

In a traditional instructional setting, coaching is constrained by time availability and the physical presence of instructors to observe and support learning. In particular, coaching is generally unavailable while learners are performing tasks outside the classroom or off the class schedule. This constraint can be alleviated, or at least reduced, by groupware and other collaborative tools such as computer conferencing and e-mail. Certainly, one major advantage of e-mail and computer conferencing is this ability to break the temporal and spatial boundaries of a traditional learning environment. Learners, while conducting case-based learning, are immediately able to send questions to experts or peers via e-mail or to post questions on the computer conference and thus receive prompt online help. Also, learners can look up online problem solving strategies and advice while performing tasks.

\section{Scaffolding}

The key point of scaffolding is to provide learners with support at the appropriate levels and at the right time. A requisite to such support is an accurate diagnosis of the learner's current skill level. The online diagnosis can be conducted, and periodic checks made by asking learners to answer questions stored in the instructional library. In response to the results, experts can direct learners toward relevant instructions, also stored in the instructional library, or work with learners on the difficulties they cannot yet manage. In addition, by examining learners' messages on e-mail, on the computer conference, or in their learning activities recorded on the shared workspace, experts are able to diagnose the learners' current progress and provide needed help.

\section{Articulation}

Learners can look up online reflective questions to articulate their knowledge and thinking processes during the process of case-based learning. Or, experts can post questions on the computer conference and ask learners to articulate their understanding of concepts and procedures. For example, during the problem analysis, experts can post questions about how learners analyze the business situation and how they make assumptions about the underlying causes of problems. In fostering articulation, when learners post their answers on the computer conference, other learners can analyze and critique the answers as a 
method of articulation. Additionally, by constructing their knowledge using hypermedia functions, learners can articulate their knowledge, reasoning, or problem-solving processes.

\section{E. Reflection}

One major advantage of using computers in learning is that certain versions of learning activities can be automatically recorded on the computer for later analysis. Similar to a tape recorder in the think-aloud method, the shared workspace keeps a record of learners' questions and answers during the process of case-based learning. These questions and answers reflect the perspectives and strategies of their problemsolving processes. A learner can thus "replay" his or her own thinking stored on the shared workspace and compare it with others. By comparing his or her solutions with peers' solutions, the learner can gain multiple perspectives of a case and its solutions. For instance, a learner's solutions can be compared with expert solutions in the instructional library in order to disclose weaknesses and strengths in his or her problem-solving skills. At the same time, facilitators or researchers might find these recordings both pedagogically and psychologically enlightening.

\section{F. Exploration}

Encouraging learners to independently pursue investigations is the essential provision of an exploratory learning environment. The instructional library provides learners with an enriched environment for this exploration. First, online searching strategies teach learners how to explore a domain productively. Second, a case can be represented in hypermedia formats and hence in dynamic panoramas. Learners can study a case from different perspectives and find their own insights. Third, the easy modification of computer-based information allows learners to control the manipulation of information in a business problem while exploring possible alternative solutions and related problems. Learners might be thus motivated to come up with something more dynamic in the way of solutions. Fourth, the full-time availability of computer tools and the instructional library gives learners the freedom to explore at will. This encourages them to effectively function in a problem-solving mode at all times. Finally, the hypermedia functions of these tools enable learners to flexibly construct their knowledge and thus invite them to explore and pursue diverse problem-solving courses.

In this electronic cognitive apprenticeship environment, learners work their way electronically through basic knowledge acquisition and case problem solving processes. Learners with different backgrounds, using their own networked workstations, identify and analyze case problems. These learners look for key facts and post them in the shared workspace for brainstorming and generating ideas. Comments and opinions are exchanged by e-mail and computer conferencing and are loaded into peer workstations or the shared workspace via electronic networks. Online domain knowledge is useful for checking new concepts, terminology, definitions, and notions that are introduced in the problem-solving processes.

In a cognitive apprenticeship, learners are able to post various facts to the computer conference for online discussions. During these online discussions, they can call up online strategies and instructions for clarification and enlightenment. For example, in a "Concern Analysis" case, learners can look up instructions about concepts for Concern Analysis. The instructions can also be used to support their rationales for problem analysis and alternative solutions. During the analysis of problems and solutions, various computer analytical tools and business analysis models are available to help learners in the analysis processes and to support their subsequent decisions. Using these tools, they can compare evaluation results with one another. Multiple perspectives can be brought in to sharpen their analyses. Learners can rationalize and mediate differences with online discussions. Once optimal decisions are identified, learners can use cognitive tools to lay out action plans and to offer the results to experts and peers for feedback and comments.

In the above paragraphs, we have elaborated how the six instructional methods of cognitive apprenticeship can be enhanced through groupware tools. It is summarized in Table 2. 
Table 2. Summaries of electronic cognitive apprenticeship

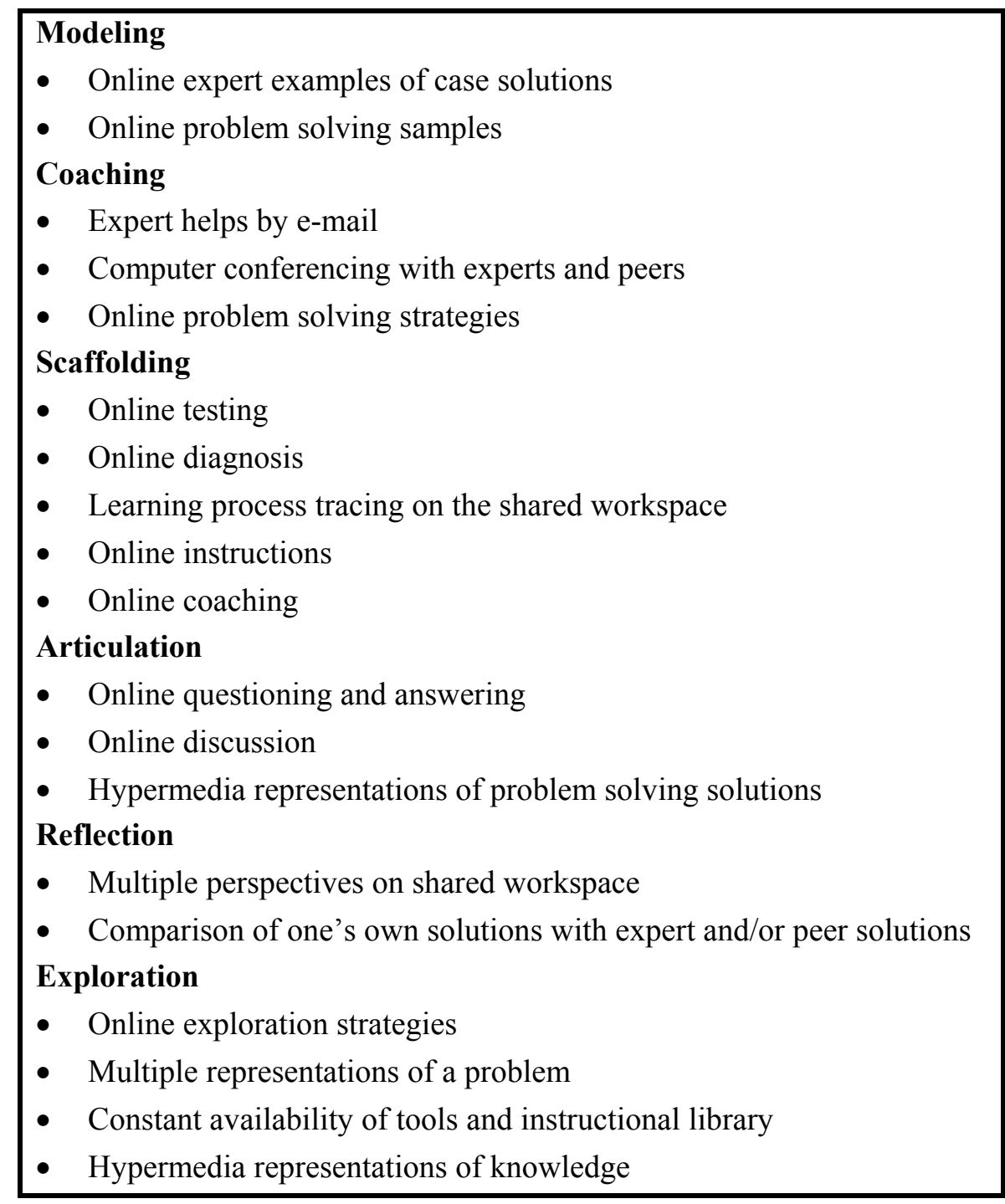

\section{The Actual Design of UNCLE}

The design framework of a GBLE takes case-based learning and cognitive apprenticeship as the theoretical ground. This framework leads to the actual design of UNCLE using Lotus Notes. The previous sections of this article have described how to apply the principles of electronic cognitive apprenticeship and collaborative case-based learning in the design of UNLCE. This section presents the snapshots of actual UNCLE to help readers gain better understanding. We start with a brief introduction of the subject matter of UNCLE -- Root Cause and Decision Analysis (RC\&DA) -- and follow with the descriptions of the main menu of UNCLE and its six primary modules.

\section{A. RC\&DA}

UNCLE adopted its content from a training course, RC\&DA. The course was initiated in the 1960s by a company called Kepner and Tregoe Associates. At that time, it began with a best-selling book called The Rational Manager. The authors of the book, Charles Kepner and Ben Tregoe, then wrote seminars with assistance from AutoCompany, Autoparts' parent company (pseudonyms). Later, AutoCompany began to adopt a different version of RC\&DA, developed by a different vendor, Business Process Inc. The 
course taught knowledge and skills in (a) Concern Analysis, (b) Problem Solving, (c) Decision Making, and (d) Planning.

\section{Course topics:}

(a) Concern Analysis teaches methods for effective analysis of any situation. It shows a simple, fourstep process to turn broad, general areas of concern into specific attachable issues. After priorities are set, each issue is addressed with one of the following thinking strategies: Problem Solving, Decision Making, or Planning.

(b) Problem Solving is the systematic organization and evaluation of information to determine the true cause of a problem. The knowledge of the true cause of a problem can be critical in determining what should be done to correct it.

(c) Decision Making is used to select the best action from closely competing, independent alternatives. It helps assure that a decision maker will make the best possible choice that his or her experience, judgment, and the available information will allow.

(d) Planning is used to identify all the steps needed to implement a decision. The planning process incorporates a simple method to trouble shoot a plan, so the planner can anticipate problems and develop preventive and contingent actions.

\section{B. UNCLE}

UNCLE is a groupware-based collaborative learning system constructed using Lotus Notes. It allows users to collaboratively learn the subject matter, RC\&DA, using networked computers without being confined to time and space boundaries. Figure 3 shows UNCLE's entry screen. To help learners get into UNCLE quickly, the entry screen provides links to the online tutorial and to the brief introduction to UNCLE itself (Help-About) and to UNCLE functions (Help-Using). Context-sensitive helps are also available to learners throughout UNCLE. For example, each document in UNCLE has a Help function to explain how the functional buttons associated with that particular document work. These help functions provide online instructions to shorten the learning curve for command of UNCLE. Clicking on the Main Menu button will present either the facilitator menu (see Figure 4) or the student menu, depending on the user's status.

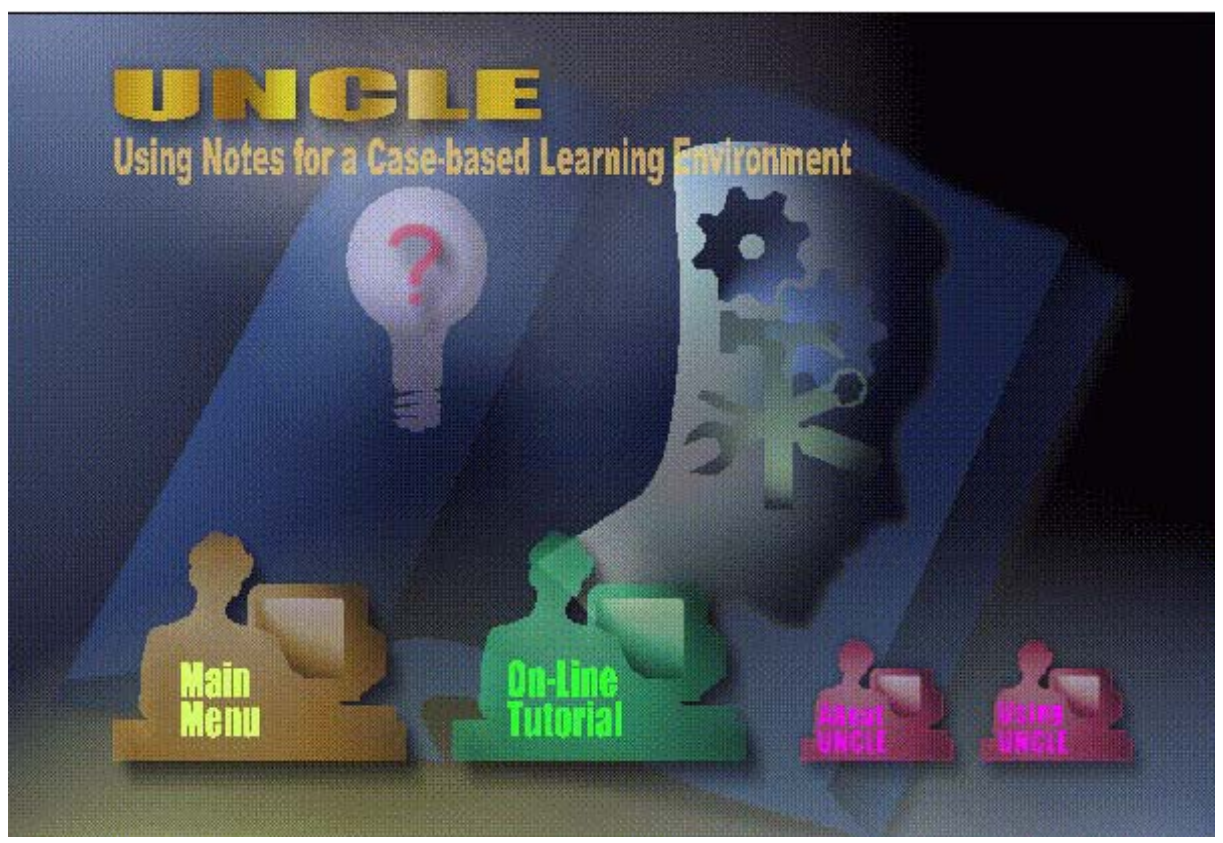

Figure 3. UNCLE's entry screen 


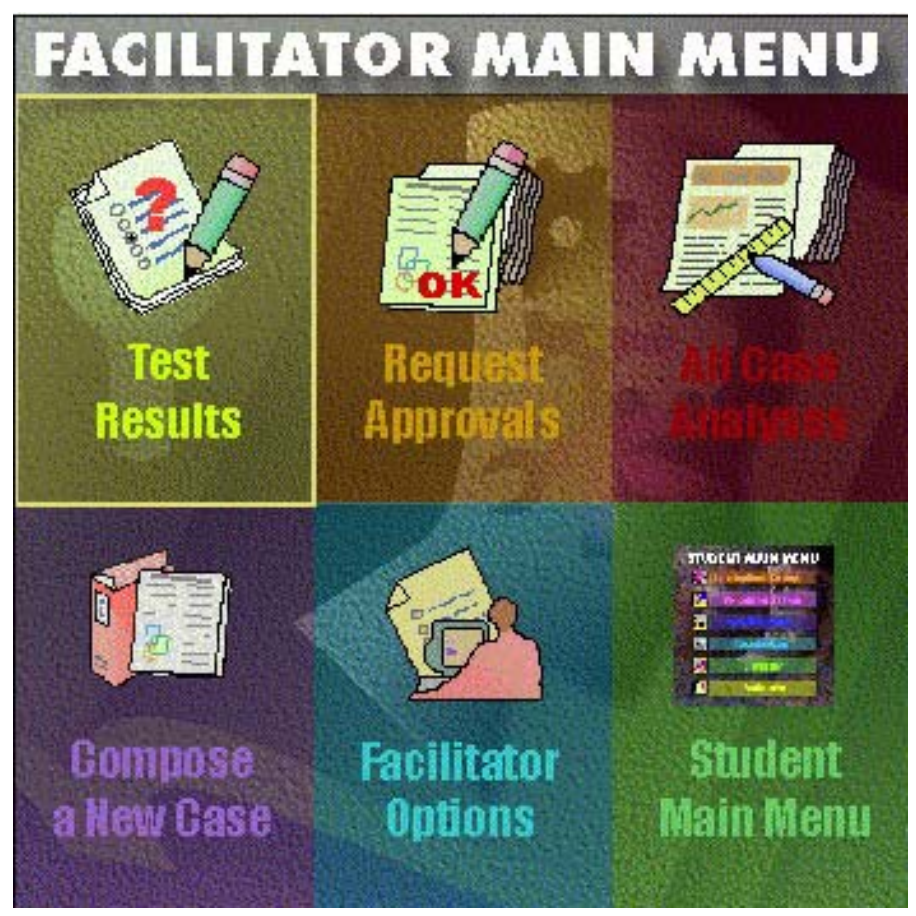

Figure 4. UNCLE's facilitator menu

\section{Student Main Menu}

There are six main modules in UNCLE -- Learning Basic Concepts, Concept Tests Taken, Case Descriptions, Case Analyses, Discussion, and Bookmarks -- as presented in the main menu of UNCLE (see Figure 5). The structure of the main menu also embodies three steps of learning processes. First, a learner acquires basic concepts by reading materials in Learning Basic Concepts and taking tests for selfevaluation and expert feedback. Once the learner has a grasp of the basic concepts, he or she advances learning to the next level by reading cases and conducting case analyses. Through case analysis, learning can be enhanced through online discussion by comments and feedback from more-able peers and experts. The whole database of UNCLE also serves as the reference library when learners apply what they learn. Online RC\&DA templates (see Figure 6 for an example) and online guidance provide performance support when learners submit in real-life work problems to solve. The online dialogues among experts and learners can deepen RC\&DA concepts and sharpen problem-solving skills of employees on the job. 


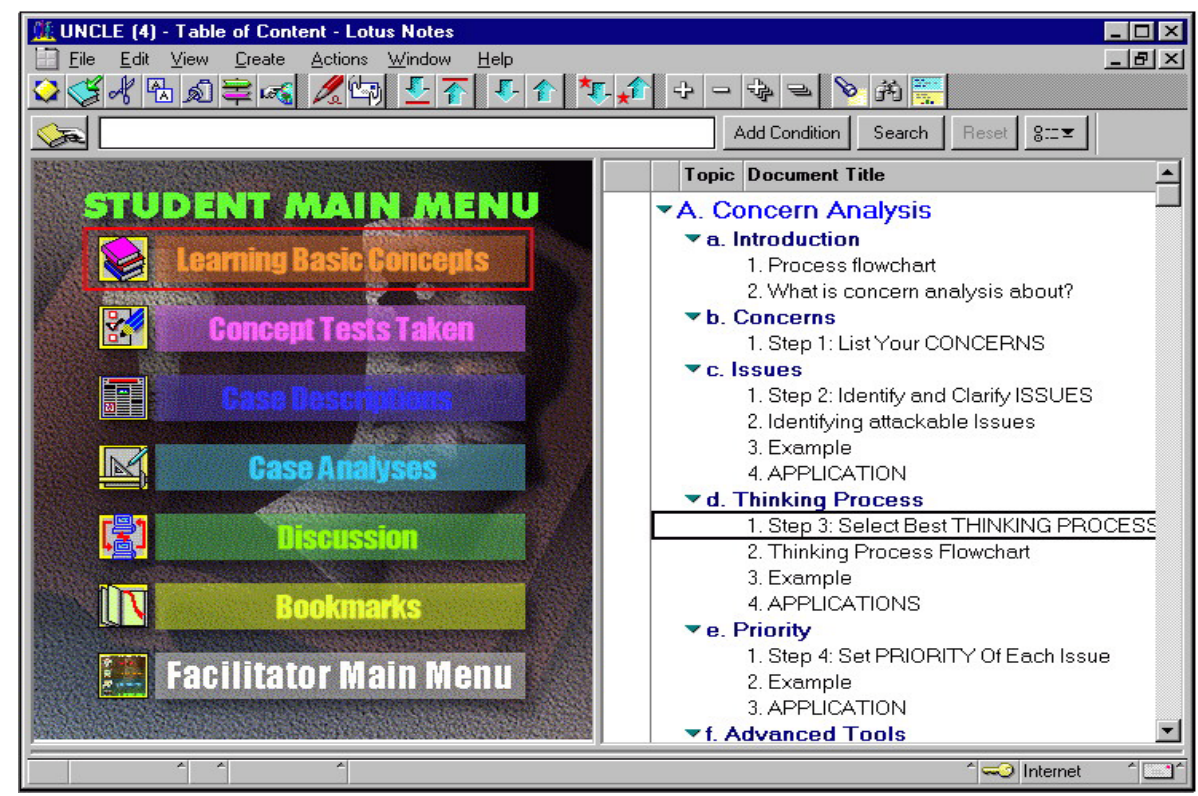

Figure 5. Student main menu of UNCLE

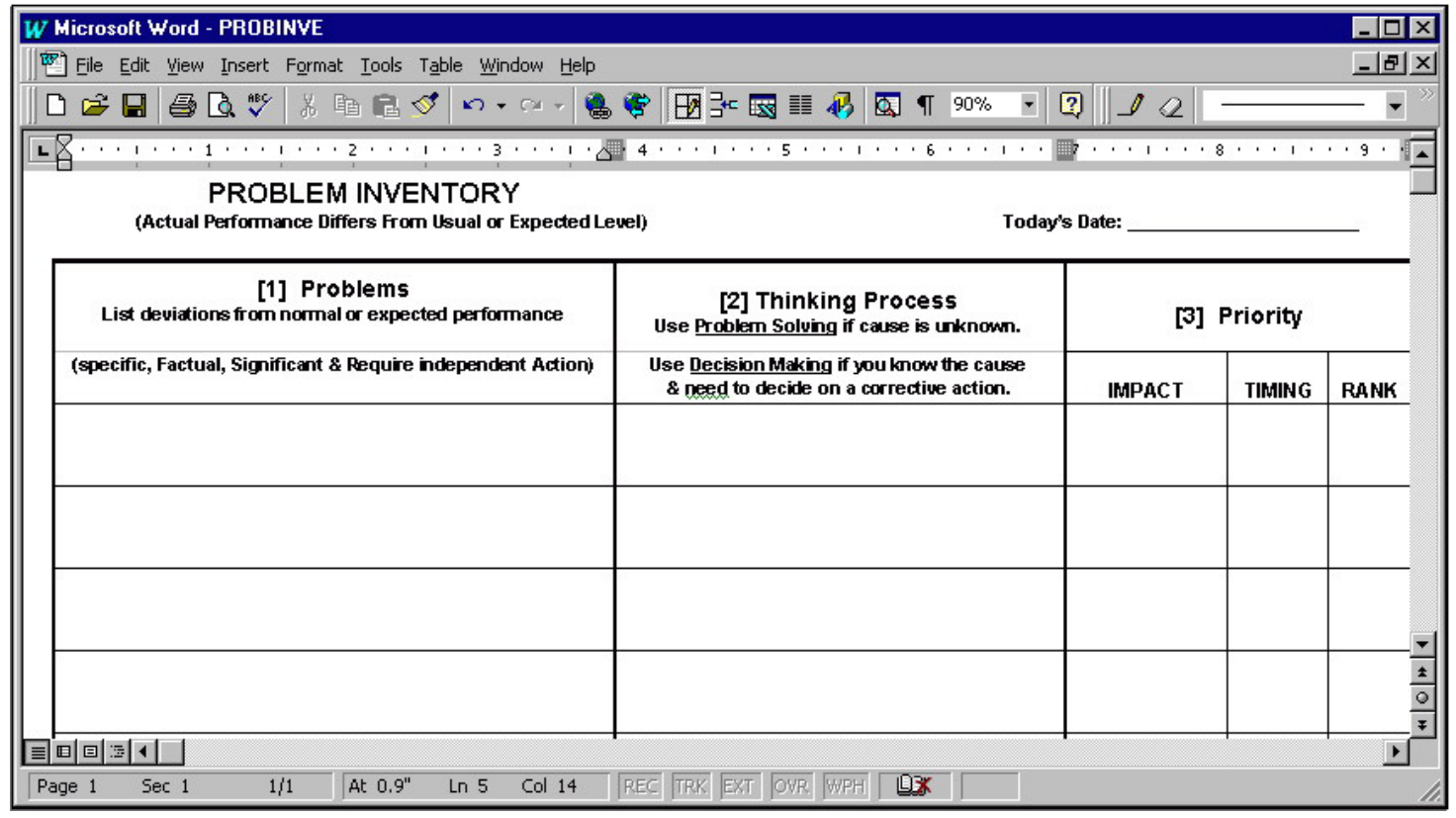

Figure 6. An online template of "Problem Inventory"

\section{Learning Basic Concepts}

The basic materials of RC\&DA are contained in this module. When the learner clicks the Learning Basic Concepts button from the main menu, the table of contents of RC\&DA is shown. Double-clicking on the title of a document opens the document. Each document contains a "page" of the RC\&DA content as depicted in Figure 7. On the top of each document are the functional buttons that help the learner to navigate in the database. The document also contains hypertext links for branching to linked pages. The Find button allows the learner to quickly locate the desired documents by keywords. Once the learner 
finishes reading a section of RC\&DA, he or she can click on the Test button to take either a multiplechoice test or a short-answer question test.

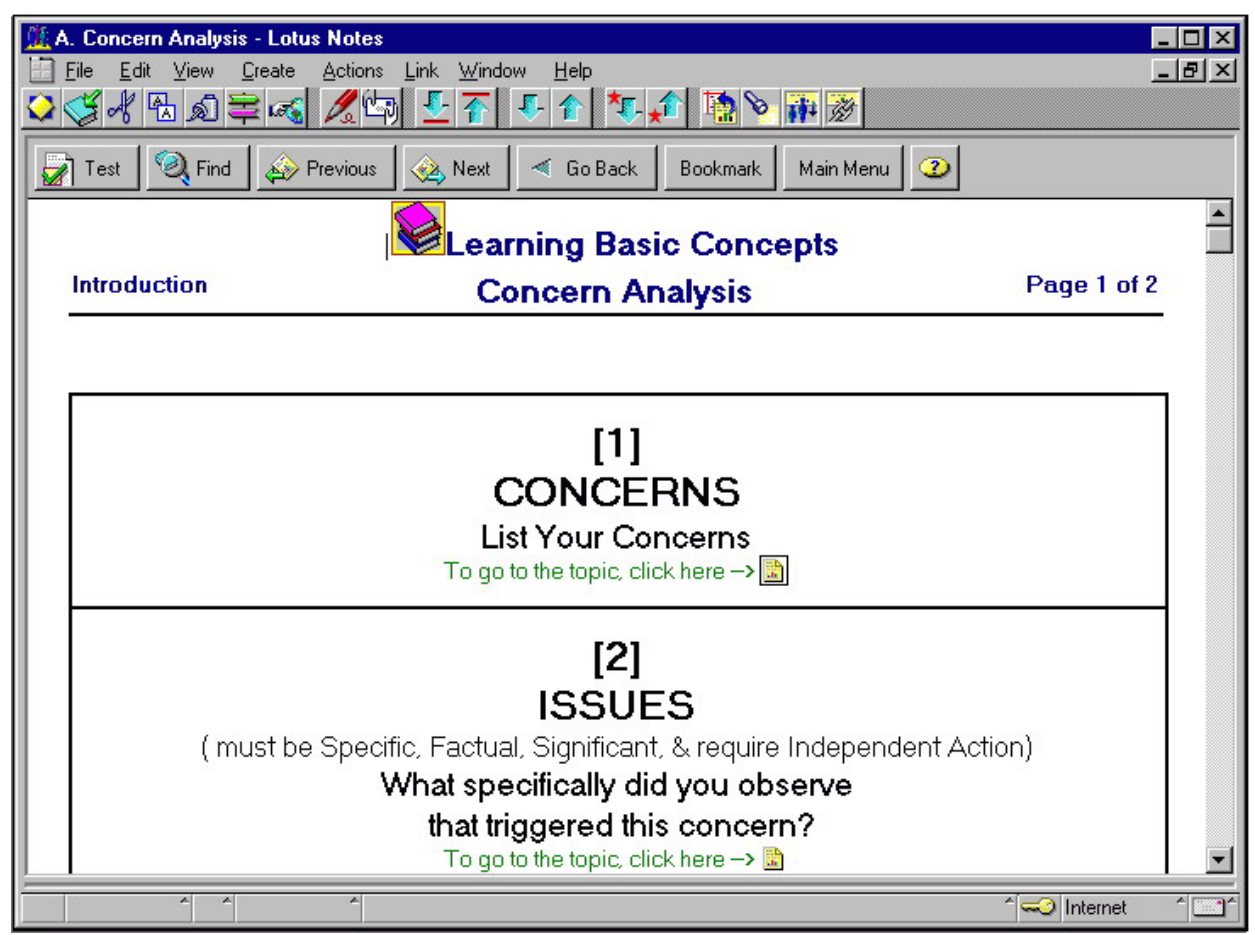

Figure 7. A document in Learning Basic Concepts

\section{E. Concept Tests Taken}

In Concept Tests Taken, the learner is able to see the tests he or she has taken before (see Figure 8 for a multiple choice test example). The learner can modify the answers of a test as many times as he or she wants. All the test results of a particular test are saved and time-coded for the learner and the facilitator to assess the learning progress. After the learner finishes a test, he or she can view the correct answers by clicking on the Answer button. Each "answer" document contains hyperlinks to the origins of all test questions in Learning Basic Concept for further reference. Before the learner is able to view the correct answers, a copy of his or her current answers is automatically routed to the facilitator for evaluation and feedback (see Figure 9). 


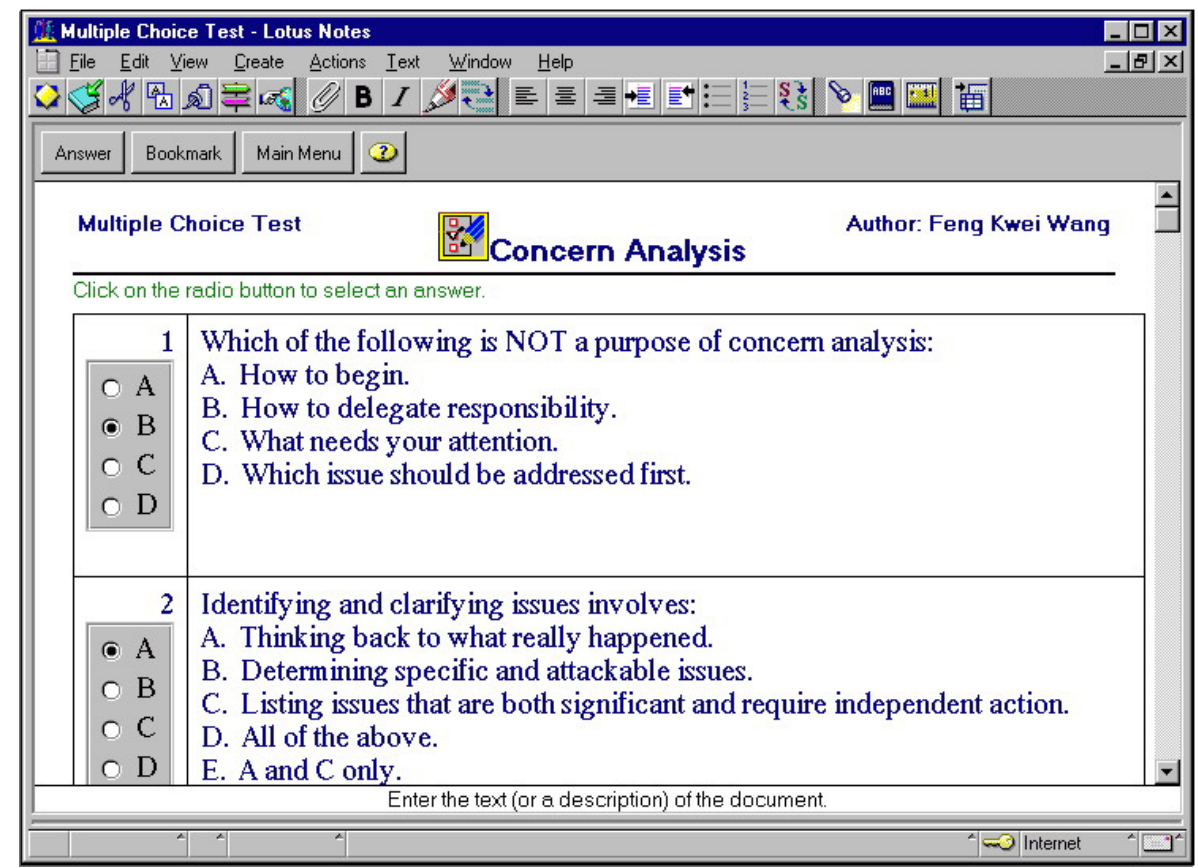

Figure 8. A multiple choice test example

\begin{tabular}{|c|c|c|c|c|}
\hline $\begin{array}{l}\text { To: } \\
\text { From: } \\
\text { Date: } \\
\text { Subject: }\end{array}$ & \multicolumn{3}{|l|}{$\begin{array}{l}\text { Feng Kwei Wang } \\
\text { Robert T Rhodes } \\
\text { 11/06/98 09:58:03 PM EST } \\
\text { Multiple Choice Test Result }\end{array}$} & \\
\hline \multicolumn{4}{|c|}{$\begin{array}{l}\text { The learner Robert T Rhodes has finished the multiple choice test on Concern Analysis and submitted the test result a } \\
\text { the time of } 08 / 02 / 98 \text { 11:35:39 AM EST. Here is the test result: }\end{array}$} & \\
\hline Answer & Question & $\begin{array}{l}\text { Correct } \\
\text { Answer }\end{array}$ & Result & \\
\hline $\begin{array}{l}1 \\
\mathbf{B}\end{array}$ & $\begin{array}{l}\text { Which of the following is NOT a purpose of concern analysis: } \\
\text { A. How to begin. } \\
\text { B. How to delegate responsibility. } \\
\text { C. What needs your attention. } \\
\text { D. Which issue should be addressed first. }\end{array}$ & B & Correct & \\
\hline $\begin{array}{l}2 \\
\mathbf{D}\end{array}$ & $\begin{array}{l}\text { Identifying and clarifying issues involves: } \\
\text { A. Thinking back to what really happened. } \\
\text { B. Determining specific and attackable issues. } \\
\text { C. Listing issues that are both significant and require independent action. } \\
\text { D. All of the above. } \\
\text { E. A and C only. }\end{array}$ & $\mathrm{D}$ & Correct & \\
\hline 3 & The nrocess of senaratino an iscue from other iscues includes. & $F$ & Wrong & $\nabla$ \\
\hline
\end{tabular}

Figure 9. A multiple choice test result sent to the facilitator for evaluation and feedback

\section{F. Case Descriptions}

In Case Descriptions, learners are provided with case descriptions for different RC\&DA sections (see Figure 10). These can be analyzed by applying the concepts and tools introduced in Learning Basic Concepts. In the present system, there are roughly a dozen two-page cases. While these solely rely on text and graphics, future versions will include video streaming and other technology enhancements. There are two types of case descriptions - sample cases and working cases. Sample cases and their solutions teach case analysis by example. Working cases are either practice cases that learners can work on to sharpen their case analysis skills or real-world cases that learners bring in from their workplaces. Learners can learn how to conduct a particular case analysis by looking at a sample case and its case 
solution. Or, they can proceed to case analysis by clicking on the Case Analysis button after reading a working case description (see Figure 11). If the learner has not worked on the case before, clicking on this button brings up a blank case analysis form and lets him or her work on the case analysis in MS Word. Otherwise, the existent case analysis is brought up and the learner can modify it.

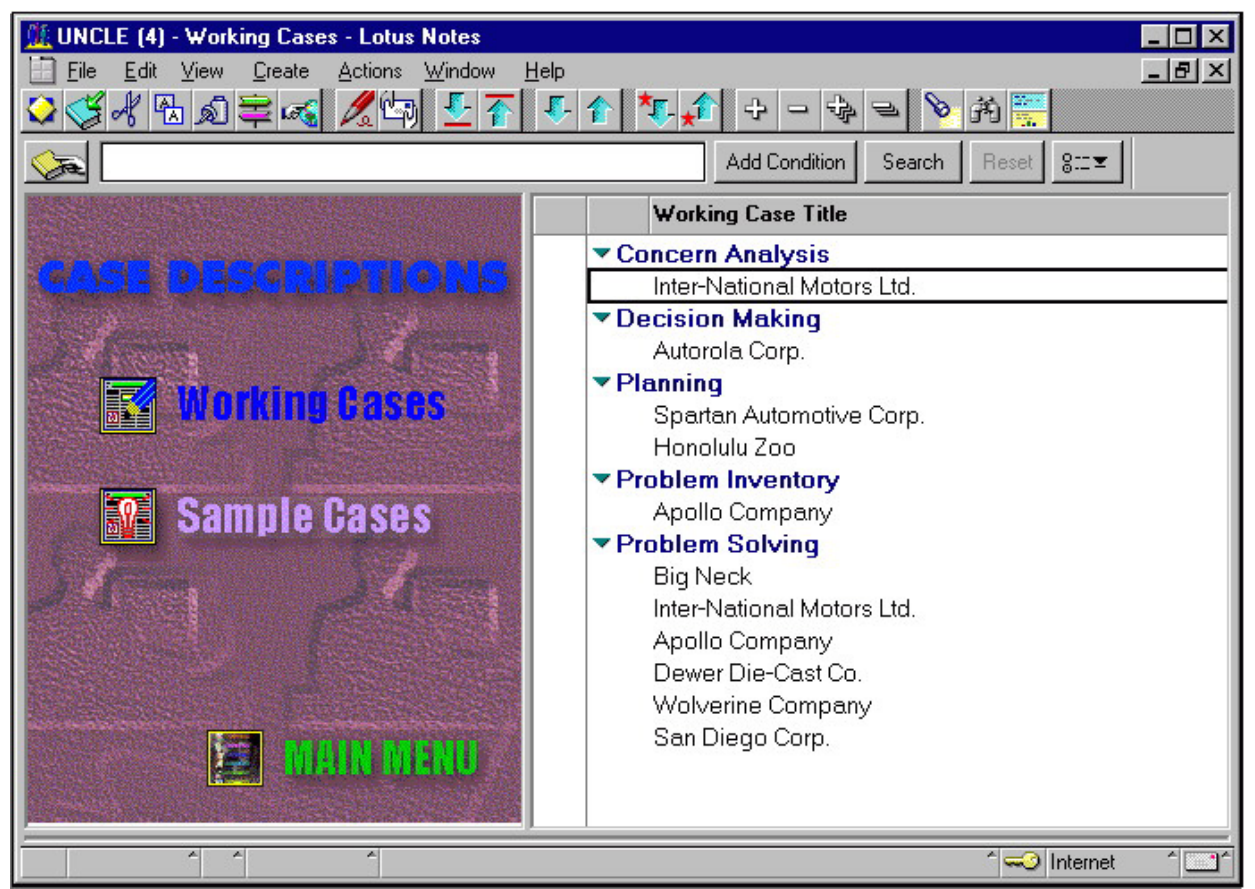

Figure 10. Case description list

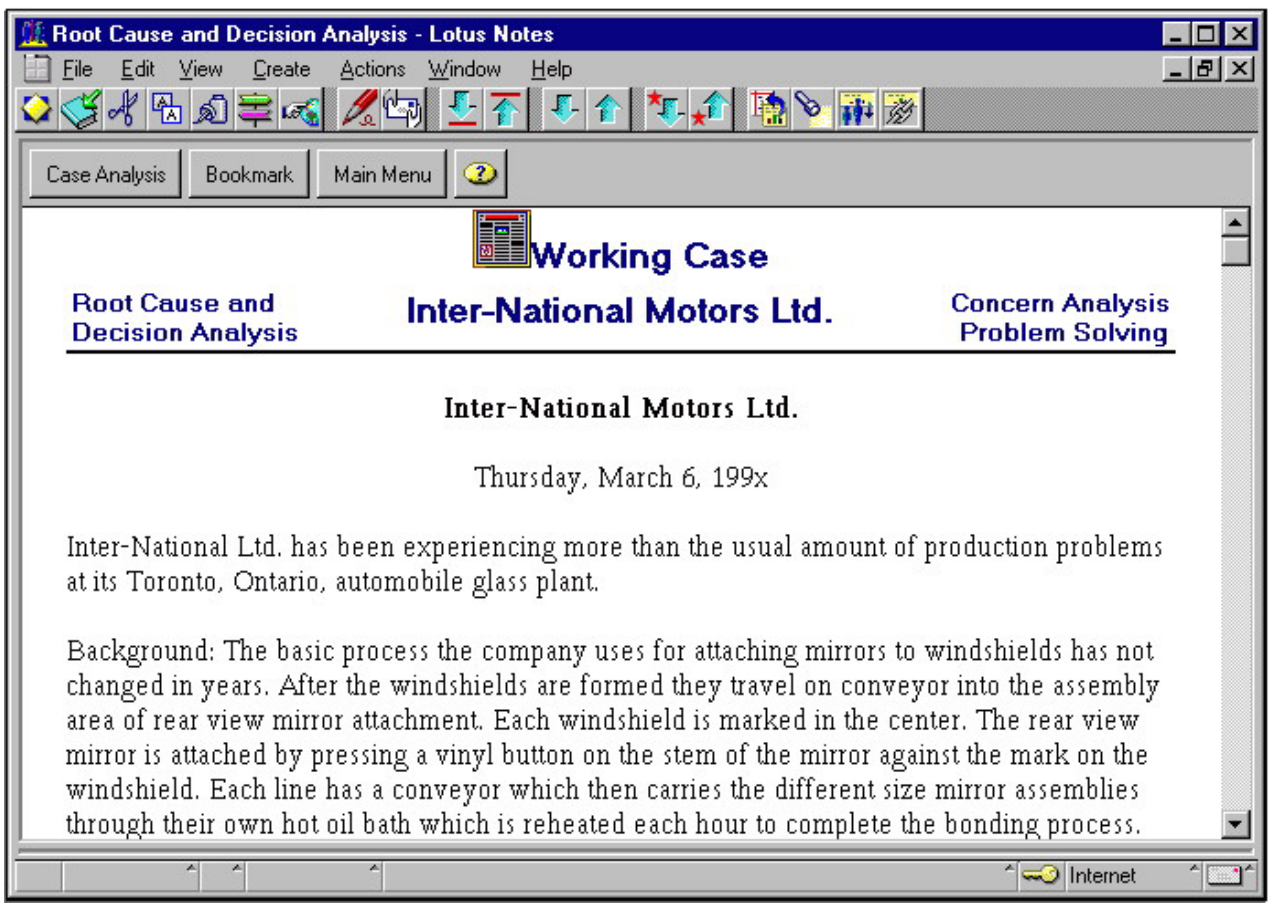

Figure 11. Case description document 


\section{G. Case Analyses}

Clicking on the Case Analyses button from the main menu brings up the list of case analyses that the learner has worked on previously. Working on Case Analyses helps the learner use the tools and apply the concepts that are learned from the Learning Basic Concepts module to "real world" cases. As indicated in Figure 12 and 13, in the Case Analysis module, the learner is able to:

- Edit existing case analysis documents,

- View the expert solution of a case analysis,

- View case analyses conducted by other learners (peer solutions) and read all comments recorded concerning a particular case analysis,

- Make a comment on the case analysis which the learner is reading, or

- Make a comment on a previously recorded comment that the learner is presently reading.

Such tools enable learners to enter into a more collaborative and social world than found in most casebased learning environments. Before the learner is able to view the expert solution or the peer solutions of a particular case, he or she has to send a request to the facilitator for approval. This is to prevent a learner from copying others' case analyses without completing his or her own work. The learner also needs to send a request to make his or her case analysis available for other learners to make comments on the case analysis. In this way, the facilitator can ratify the quality of a learner's case analysis and provide feedback before it is made available for peers to comment. Such tools foster reflection and metacognitive processing on the part of both the learner and the facilitator. To assure the quality of peer comments associated with a case analysis, UNCLE also provides administrative functions for the facilitator to delete inappropriate comments or move misposted comments to the right case.

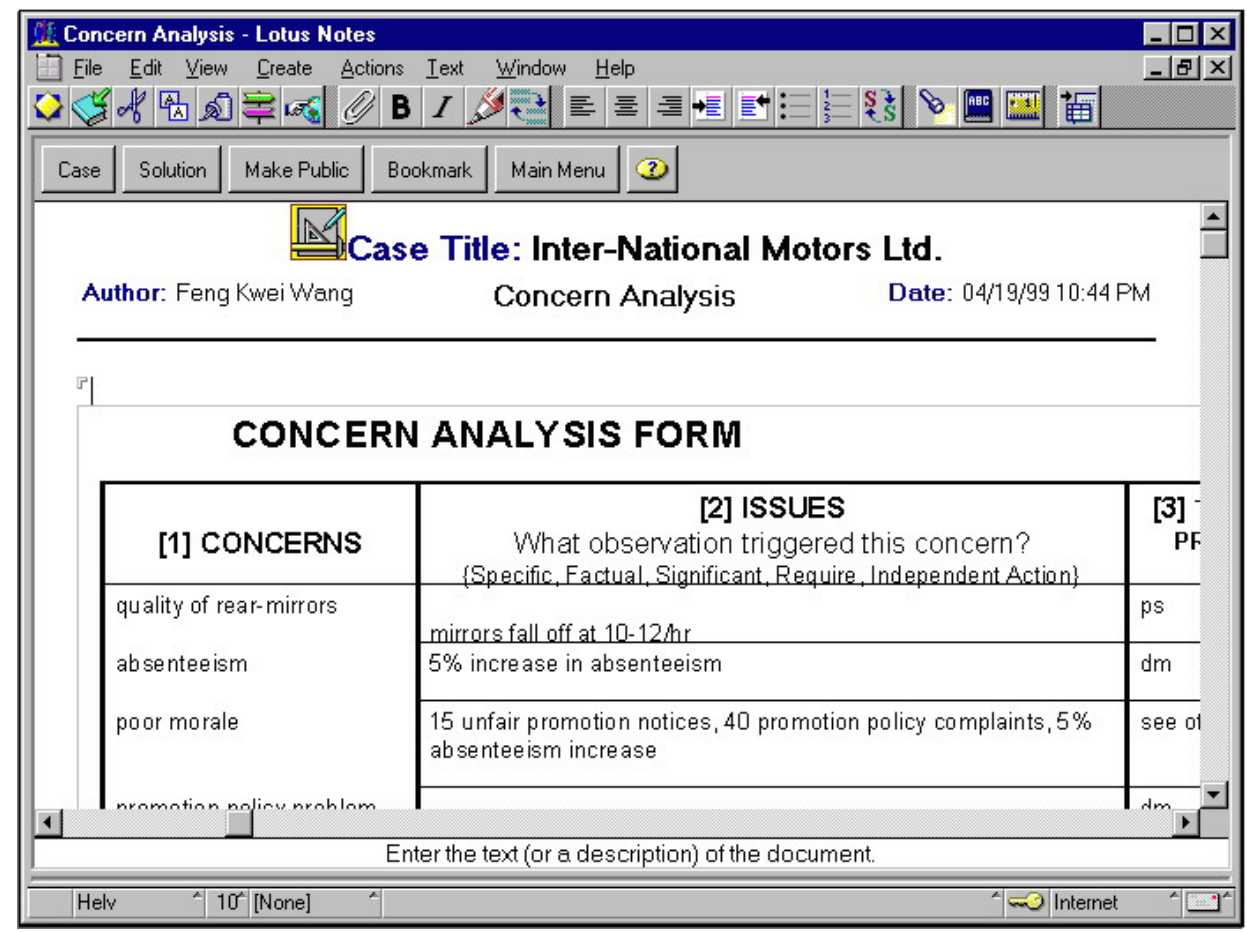

Figure 12. A case analysis document 


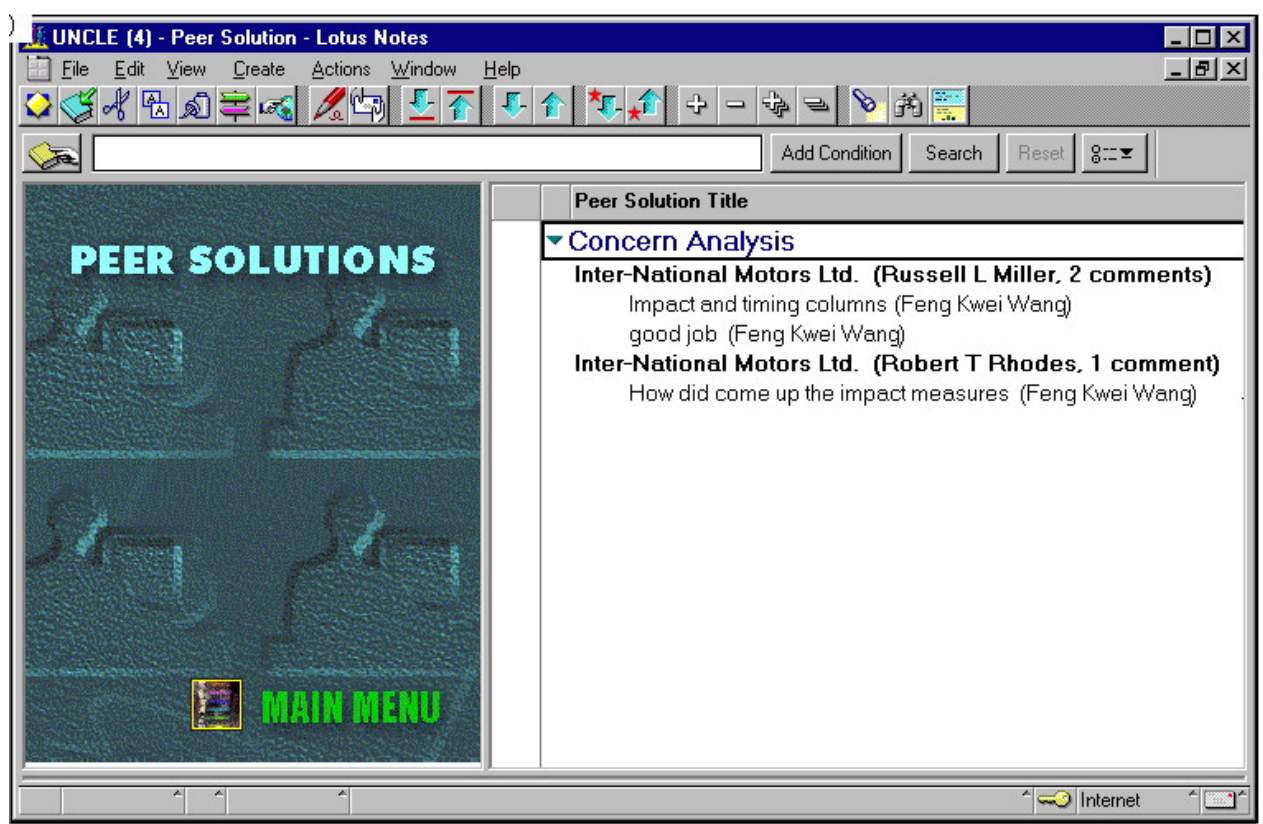

Figure 13. Peer solutions for the same case and their comments from other peers

\section{H. Discussion}

Given the collaboration and student apprenticeship focus of this system, it is vital to have discussion and negotiation tools embedded within it. Here, students enter a social space for both learning and reflecting on the task requirements. There are four options to choose from in the Discussion module: (1) Compose a new topic, (2) View existing topics by author, (3) View existing topics by category, and (4) View existing topics by date (as shown in Figure 14). Discussion allows the learner to participate in an online group discussion. He or she can compose a new discussion topic, read previously created documents, or respond to discussion topics already in progress. All UNCLE learners are able to share their ideas or exchange learning experiences with one another through this "Discussion" function. Novel technology tools alone will not guarantee heated discussion and dialogue. Our experience indicates that online discussion is fostered by significant task structuring, controversial topics, student ownership, instructor or facilitator modeling of system use, and role play [33]. 


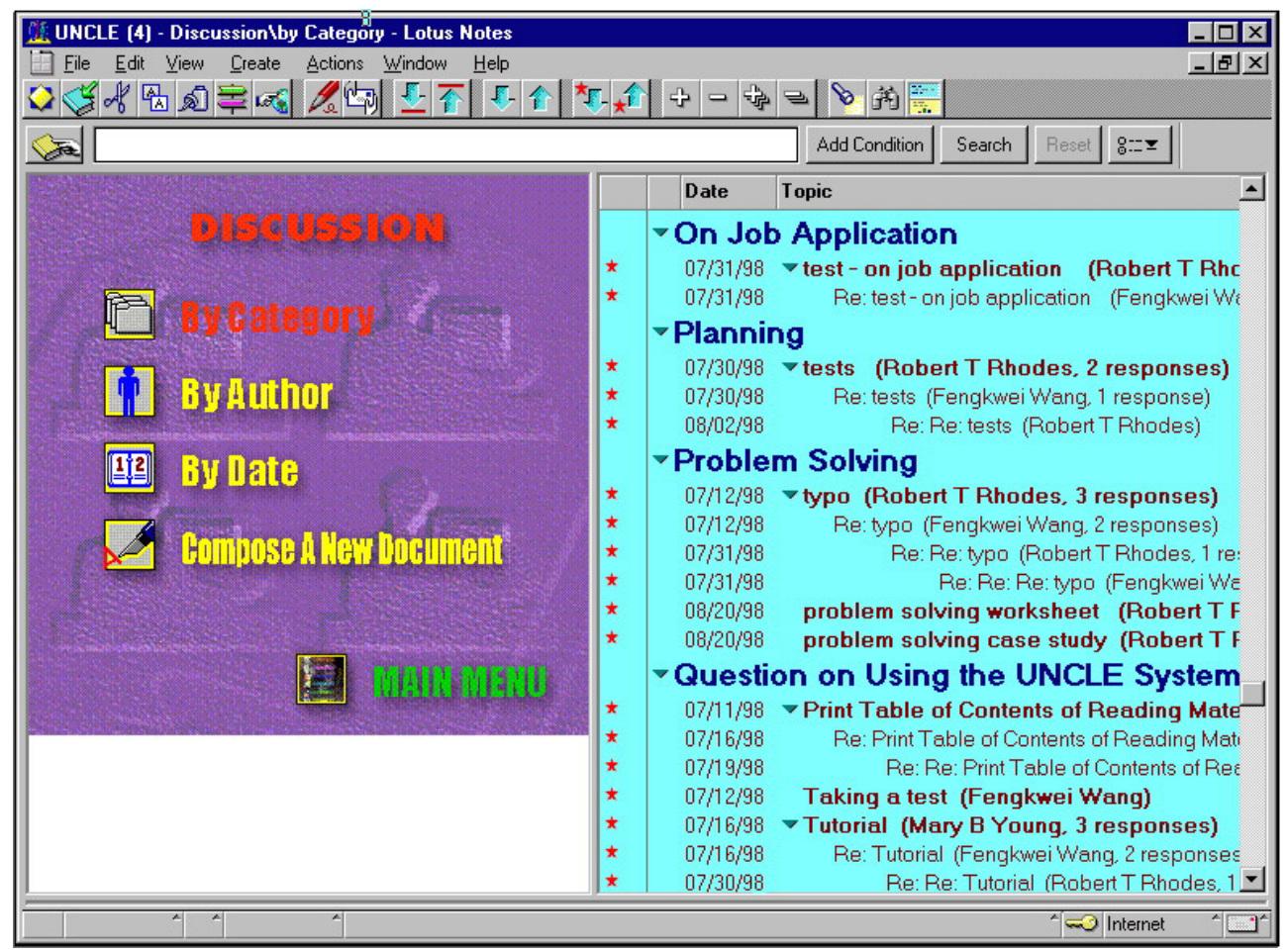

Figure 14. Discussion database

\section{Bookmarks}

A bookmark links to the location of a document so that the learner can go to the document directly by opening the bookmark. Clicking on the Bookmark button brings up the Bookmark list as shown in Figure 15. It shows the bookmarks that the learner has made previously. The learner can go to the bookmarked document directly by opening that bookmark. With complex systems like UNCLE, it is useful to facilitate such bookmarking, thereby helping learners quickly move within different tasks or activities.

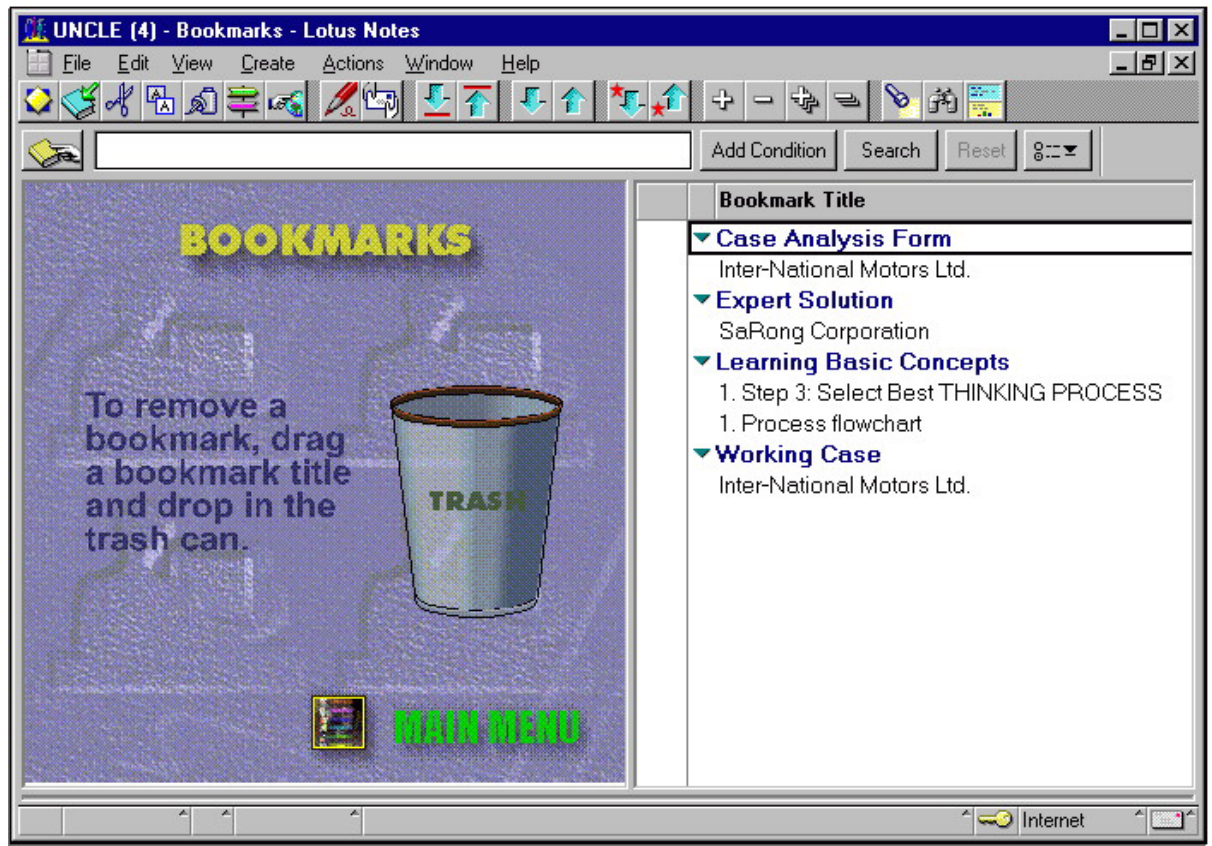

Figure 15. Bookmark list 


\section{Conclusion}

This paper responds to the imperative that the success of technology-based learning environments does not solely rely on technology. Considerations of human cognition, and the social context of that thinking, take precedence over technology. To this aim, we have proposed a design framework that integrates cognitive apprenticeship, case-based learning, and groupware technology to create a GBLE. The aim of this framework is to "intellectualize" technology by grounding learning theories in a system design that effectuates learning. We believe that the essence of groupware technology in this learning environment is warranted on the challenges of creating a meaningful learning context and on the support of cognitive apprenticeship and case-based learning.

In this paper, we have illustrated how to actualize this GBLE framework in detail by constructing UNCLE. Once it was created, UNCLE was immediately pilot tested and analyzed. The pilot findings showed encouraging results on UNCLE's learning effectiveness. When asked how pilot participants were doing with learning the subject matter, the facilitator, also the subject matter expert was surprised at how much the participants had learned and wrongly assumed that the participants had been handpicked for the pilot. At the same time, the findings also revealed a set of sociotechnical factors for organizations to deliberate when they want to develop and implement GBLE's. For instance, instructors need to consider factors that motivate people to adapt to learn, and participate in GBLE learning tasks. Additionally, they need to understand the underlying organizational support and the mechanics of the technology and its processes (see [34] for an extended discussion of such factors and issues).

At the start of this new century, we certainly face opportunities to share, to collaborate, and to reason with tools unimaginable at the dawn of the last century. Many doors to this century will swing open if we begin to develop more sophisticated tools to foster learner collaboration, case-based reasoning, and higher levels of cognitive processes. As such tools are developed, research on learner collaboration in online environments should lead to interesting new learning and instruction models and findings. Of course, it is also vital to understand the role of the facilitator in fostering learning in such environments. Fortunately, advances in groupware technology have paralleled a shift in psychological theory and instructional design perspectives that draw attention to interactive, distributed, and learner-centered environments. UNCLE and other similarly designed systems signal such change and highlight the need for extensive testing and discussion. They also provide a glimpse into learning environments that will soon become commonplace.

\section{References}

1. Salomon, G., Novel Constructivist Learning Environments and Novel Technologies: Some Issues to be Concerned With. Research Dialogue in Learning and Instruction, Vol., No. 1, pp. 3-12, 1998.

2. Gentry, C. G., Educational Technology: A Question of Meaning. In G. J. Anglin (Ed), Instructional Technology: Past, Present, and Future, Englewood, CO: Libraries Unlimited, Inc, pp. 1-10, 1991.

3. Heinich, R., The Proper Study of Instructional Technology. ECTJ, Vol. 32, No. 2, 67-87, 1984

4. Collins, A., Design Issues For Learning Environments. In Vosniadou, S., Corte, E. D., Glaser, R., and Mandl, H. (Eds.), International Perspectives on the Design of Technology-Supported Learning Environments, Mahwah, New Jersey: Lawrence Erlbaum Associates, pp. 347-361, 1996.

5. Brown, J. S., Collins, A., \& Duguid, P., Situated Cognition and the Culture of Learning. Educational Researcher, Vol. 17, pp. 32-42, 1989.

6. Lave, J., \& Wenger, E., Situated Learning: Legitimate Peripheral Participation. New York: Cambridge University Press, 1991.

7. Lave, J., Cognition in Practice: Mind, Mathematics, and Culture in Everyday Life. New York: Cambridge University Press, 1988. 
8. Collins, A., Brown, J. S., \& Newman, S., Cognitive Apprenticeship: Teaching the Crafts of Reading, Writing, and Mathematics. In Resnick, L. B. (ed.), Knowing, Learning, and Instruction: Essays in honor of Robert Glaser. Hillsdale, NJ: Lawrence Erlbaum Associates, Inc, pp. 453-494, 1989.

9. Glaser, R., Ferguson, E. L., \& Vosniadou, S., Introduction: Cognition and the Design of Environments for Learning. In Vosniadou, S., Corte, Glaser, E. D., R., and Mandl, H. (Eds.), International Perspectives on the Design of Technology-Supported Learning Environments. Mahwah, New Jersey: Lawrence Erlbaum Associates, pp. 1-9, 1996.

10. Tharp, R., Institutional and Social Context of Educational Reform: Practices and Reform. In Forman, E. A., Minnick, N., and Stone, C. A. (Eds.), Contexts for Learning: Sociocultural Dynamics in Children's Development. New York: Oxford University Press, pp. 269-282, 1993.

11. Tharp, R., \& Gallimore, R., Rousing Minds to Life: Teaching, Learning, and Schooling in a Social Context. Cambridge, MA: Cambridge University Press, 1988.

12. Bonk, C. J. \& Kim, K. A., Extending Sociocultural Theory to Adult Learning. In Smith, M. C. and Pourchot, T. (Eds.), Adult Learning and Development: Perspectives from Educational Psychology. Mahwah, NJ : Lawrence Erlbaum Associates, 1998.

13. Vygotsky, L. S., Mind in Society: The Development of Higher Psychological Processes. Cambridge, MA: Harvard University Press, 1978.

14. Blumenthal, J., Use of the Case Method in MBA Education. Performance Improvement Quarterly, Vol. 4, No. 1, pp. 5-13, 1991.

15. Christensen, C. R., Teaching and the Case Method: Text, Cases, and Readings. Boston, Mass.: Harvard Business School, 1987.

16. Hartman, L. D., Business Communication and the Case Method: Toward Integration in Accounting and MBA Graduate Programs. The Bulletin, pp. 41-44, September, 1992.

17. Romiszowski, A., Introduction (Special Issue on Case Studies). Performance Improvement Quarterly, Vol. 4, No. 1, pp. 3-4, 1991.

18. Williams, S. M., Putting Case-based Instruction into Context: Examples from Legal and Medical Education. The Journal of The Learning Sciences, Vol. 2, No. 4, pp. 367-427, 1992.

19. Bonk, C. J., Hansen, E. J., Grabner, M. M., Lazar, S., \& Mirabelli, C., Time to "Connect": Synchronous and Asynchronous Case-based Dialogue among Preservice teachers. In Bonk, C. J., \& King, K. S. (Eds.), Electronic Collaborators: Learner-centered Technologies for Literacy, Apprenticeship, and Discourse. Mahwah, NJ: Erlbaum, pp. 289-314, 1998.

20. Shulman, L. S., Revealing the Mysteries of Teacher-written Cases: Opening the Black Box. Journal of Teacher Education, Vol. 42, No. 4, pp. 263-272, 1991.

21. Bonk, C. J., Malikowski, S., Angeli, C., \& East, J., Web-based Case Conferencing for Preservice Teacher Education: Electronic Discourse from the Field, Journal of Educational Computing Research, Vol. 19, No. 3, pp. 267-304, 1998.

22. Bonk, C. J., Medury, P. V., \& Reynolds, T. H., Cooperative Hypermedia: The Marriage of Collaborative Writing and Mediated Environments. Computers in the Schools, Vol. 10, No. 1/2, pp. 79-124, 1994.

23. Wilson, P., Computer Supported Cooperative Work: An Introduction. Exford, England: Intellect, 1991.

24. Ellis, C.A., Gibbs, S. J., \& Rein, G. L., Groupware: Some Issues and Experiences. In Baecker, R. M. (Ed.), Readings in Groupware and Computer-Supported Cooperative Work. San Mateo, CA: Morgan Kaufmann, pp. 9-28, 1993.

25. Kirkpatrick, D., Here Come the Payoff from PCs. Fortune, Vol. 125, No. 6, pp. 93-99, March 23, 1992.

26. Kirkpatrick, D., Groupware Goes Boom. Fortune, Vol. 128, No. 16, pp. 99-103, December 27, 1993.

27. Schrage, M., Shared Minds: The Technologies of Collaboration. New York: Randon House, 1990. 
28. McCarthy, R., Multimedia: What the Excitement's All about. Electronic Learning, Vol. 8, No. 8, pp. 26-31, 1989.

29. Harasim, L. M., Global Networks: An Introduction. In Linda, L. M. (Ed.) Global Networks: Computers and International Communication. Cambridge, MA: The MIT Press, pp. 3-13, 1993.

30. Kozma, R., The Implications of Cognitive Psychology for Computer-based Learning Tools. Educational Technology, Vol. 27, pp. 20-25, 1987.

31. Amthor, G., Interactive Multimedia in Education: Concepts and Technology, Trends, and Model Applications, Megamedia and Knowledge Systems. T.H.E. Journal, Special Issue: IBM Multimedia, pp. 2-11, September, 1991.

32. Jonassen, D. H., Acquiring Structural Knowledge from Semantically Structured Hypermedia. A paper presented in the AECT annual convention, Washington, D.C, 1992.

33. Bonk, C. J., \& Cummings, J. A., A Dozen Recommendations for Placing the Student at the Center of Web-based Learning. Educational Media International, Vol. 35, No. 2, pp. 82-89, 1998.

34. Wang, F., Using Groupware to Construct a Learning Organization: A Case Study of Enriched Learning and Information Environments. Unpublished dissertation, Indiana University, Bloomington, 1998.

\section{About the Authors}

Dr. Feng-Kwei Wang is an assistant professor in the School of Information Science and Learning Technologies at University of Missouri - Columbia. He received three advanced degrees from Indiana University - M.S. in computer science, MBA in marketing, and Ph.D. in Instructional Systems technology. Before moving to MU in August 1999, he worked on systems development projects for several Fortune 500 companies including AT\&T, IBM, Delco Electronics, and Eli Lilly. Feng-Kwei is interested in the process of designing and developing learning and information systems, the uses of multimedia technologies to enhance human learning and performance, and the design and implementation of knowledge management systems. His primary teaching areas in SISLT include information systems design and development and telecommunications and network technology.

Dr. Curt J. Bonk is a former CPA and corporate controller who received his master's and Ph.D. degrees from the University of Wisconsin in 1987 and 1989, respectively. He arrived at Indiana University (IU) in 1992 after teaching at West Virginia University for three years. Curt Bonk is now an associate professor in the Learning, Cognition, and Instruction Program within the Department of Counseling and Educational Psychology at IU. He also is adjunct in the Instructional Systems Technology Department. He received the Burton Gorman teaching award in 1999 and the Wilbert Hites Mentoring Award in 2000. In May of 1997, he was a visiting scholar at the University of Oulu in northern Finland. In November 1998, Curt was a visiting scholar at the Virtual University and TeleLearning National Center of Excellence within Simon Faser University in Vancouver, British Columbia. In 1999-2000, Curt was a Senior Consortium Research Fellow with the Army Research Institute. Currently, he is a core member of the Center for Research on Learning and Technology located in the IU School of Education. Curt is interested in enhancing college and K12 pedagogy with technological supports, scaffolded instruction, alternative instructional strategies, and nontraditional learning tools. He recently edited: "Electronic Collaborators: Learner-Centered Technologies for Literacy, Apprenticeship, and Discourse" published in 1998 by Erlbaum and was technology contributor for the 9th edition of Houghton Mifflin's educational psychology textbook, Psychology Applied to Teaching (2000) by Jack Snowman and Robert Biehler. He also has edited the first online course reader for educational psychology, published by Bell and Howell Learning and Information Company. He is President of CourseShare.com, which he founded in 1999. 